\title{
Modeling of the PG-CP4 coating hardness applied to H12M steel and subjected to laser treatment
}

\author{
Valentin Morozov ${ }^{1}$, Vladimir Gusev ${ }^{1, *}$, Alexey Morozov ${ }^{1}$, and Dmitry Gavrilov ${ }^{1}$ \\ ${ }^{1}$ Vladimir State University named after Alexander and Nikolay Stoletovs, Russian Federation
}

\begin{abstract}
The article considers the influence of the radiation power $W$, the longitudinal feed $S p r$ of the laser beam and the distance $L$ from the protective glass of the laser focusing head to the workpiece on the $P G-C P 4$ coating hardness which was applied to $H 12 M$ steel by plasma and then subjected to laser treatment. A multi-factor model is established that relates the $P G-C P 4$ coating hardness to the input process factors and allows you to quickly assign a laser treatment mode and to control it in order to improve the quality of the processed surface layer. Increasing $W, S p r$ and $L$ leads to a increase in the HV parameter. The longitudinal feed Spr of the laser beam has the greatest effect on the surface layer hardness, then followed the distance $L$ and radiation power $W$. The research results are relevant for manufacturing enterprises that implement laser processing processes of materials and design organizations that develop modern laser equipment.
\end{abstract}

\section{Introduction}

High-chromium tool steel $H 12 M$ is used to make matrix and punches of cold-pressing dies operating at pressures up to $1400-1600 \mathrm{MPa}$, as well as broaches and other cutting tools, in which the hardness of the surface layer plays an important role in ensuring high operational reliability.

Studied extensively processing is widely of laser welding surface treatment, including surface quenching of metals and alloys [1].

Also studied features of structure formation during laser processing [2], surface morphology during selective melting of metal powders [3], worked out simulations model melting of stainless steel [4].

The liquid flow and heat exchange in the melt pool $[5,6]$, mechanisms of pore formation, splashes [7], influence of surface tension on the morphology of the molten puddle, modification of the materials surface layer, laser hardening of steel and its alloys [8-10] are determined. Consided the influence of laser heat treatment on the properties of hardened surface layers, particularly the influence laser radiation power to change the hardness of the parts, increase the wear resistance of the bearing assembly [11-13].

\footnotetext{
*Corresponding author: prof_gusev@mail.ru
} 
The first studies aimed at determining a multi-factor model of steel $40 \mathrm{H} 13$ hardness after laser treatment were conducted [14].

The physical foundations of materials laser processing $[15,16]$ and highly efficient resource-saving technologies [17] have been developed.

The effect of laser quenching with a round, profiled and oscillating beam on increasing the service life of machine parts [18] and modeling of laser quenching of AISI 4140 steel [19] is considered.

The processes of laser processing of materials are characterized by a large number of independent input factors and output optimization parameters, that is, they are multi-criteria and multi-parametric.

In this regard, the most effective are not the single-factor models discussed in the considered literature sources, but the multifactorial models.

The multifactor model is a set of regression equations that connect each optimization parameter under study with several process factors that provide an interactive and dominant influence on the formation of geometric and physico-mechanical characteristics of the treated surface layer [20].

In addition, it is important for manufacturing enterprises to know mathematical models that link independent factors of processing processes with the output parameters of the surface layer quality, on the basis of which it is possible to assign processing modes.

In this regard, the development of multi-factor experimental models of laser processing processes was not given due attention.

The research purpose is to establish a multi-factor experimental model, on the basis of which elements of the laser treatment mode are assigned for providing the required hardness of the surface layer of the coating PG-CP4 .

The use of the model is relevant for enterprises that develop modern technologies for materials laser processing, but also for organizations and companies that design new highperformance laser equipment.

\section{Materials and Methods}

The hardness of the $P G-C P 4$ functional coating processed on a multipath diode laser complex was chosen as the output technological parameter. Samples made from highchromium tool alloy steel $H 12 \mathrm{M}$ and had thickness of $7 \mathrm{~mm}$ and a diameter of $30 \mathrm{~mm}$.

The hardness of the treated surface layer was measured using a microhardness device, with a minimum load on the indenter of $50 \mathrm{mN}$, a maximum load of $30 \mathrm{~N}$, and a loading speed of up to $10 \mathrm{~N} / \mathrm{min}$.

A multi-factor experiment $N=2 \wedge 3=8$ was implemented, in which the radiation power $W$, the longitudinal feed $S p r$ of the laser beam, and the distance $L$ from the protective glass of the focusing head to the workpiece surface to be processed were selected as independent factors of the laser processing process.

The upper and lower levels of independent factors were the values of the laser treatment mode elements, and the factors main levels were used during calculating the multifactor model of the coating hardness applied to steel H12M by plasma.

\section{Results}

The experiments results are presented in the planning matrix (Table 1). The coating hardness values on the Vickers scale which are presented in the rightmost column are obtained as a result of three parallel experiences for each matrix row. 
Table 1. A coating hardness of steel $H 12 M$ as a function of laser treatment modes

\begin{tabular}{|c|c|c|c|c|}
\hline \multirow{2}{*}{$\begin{array}{c}\text { Experien } \\
\text { ces }\end{array}$} & \multicolumn{3}{|c|}{ Independent factors } & Parameter \\
\cline { 2 - 5 } & $\begin{array}{c}\text { Power } \\
W, \mathrm{~kW}\end{array}$ & $\begin{array}{c}\text { Feed } \\
\text { Spr, mm/s }\end{array}$ & $\begin{array}{c}\text { Distance } \\
L, \mathrm{~mm}\end{array}$ & Hardness, \\
\cline { 2 - 5 } & $x_{1}$ & $x_{2}$ & $x_{3}$ & $\mathrm{HV}$ \\
\hline 1 & 2 & 10 & 85 & 331 \\
\hline 2 & 2 & 25 & 85 & 225 \\
\hline 3 & 5 & 25 & 60 & 329 \\
\hline 4 & 5 & 25 & 85 & 327 \\
\hline 5 & 5 & 10 & 85 & 198 \\
\hline 6 & 2 & 25 & 60 & 524 \\
\hline 7 & 5 & 10 & 60 & 246 \\
\hline 8 & 2 & 10 & 60 & 509 \\
\hline
\end{tabular}

Regression equation relating the hardness of the treated coating $P G-C P 4$ with the radiation power $W$ and the longitudinal feed Spr, has the form:

$$
\mathrm{HV}=153.54+11.75 * W+8.08 * \operatorname{Spr}
$$

The graphical interpretation of the equation (1) is represented in Fig. 1.

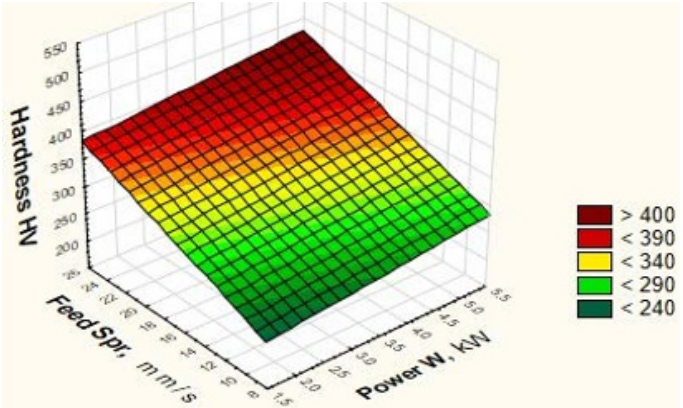

Fig. 1. 3M-XYZ surface-graph of the interactive effect of the radiation power and the longitudinal feed on the steel H12M coating hardness.

To quickly determine the laser treatment mode that provides the maximum hardness of the coating, 3M-XYZ contour plots are used for various combinations of independent factors. The 3M-XYZ contour plot of the interactive effect of the radiation power and the longitudinal feed of the laser beam on the hardness of the coating $P G-C P 4$ is shown in Fig. 2.

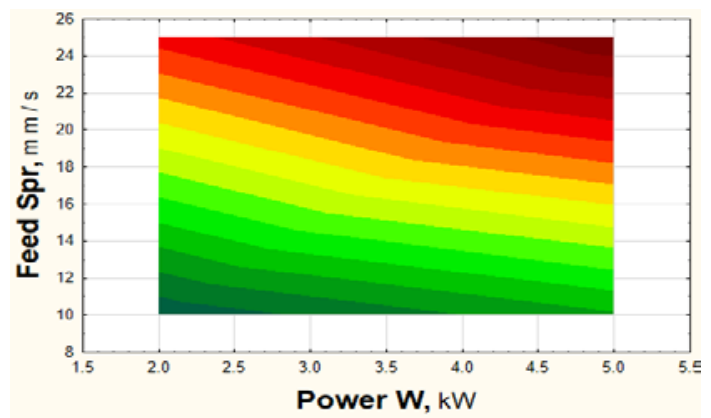

Fig. 2. 3M-XYZ contour-graph of the interactive effect of the radiation power and the longitudinal feed on the steel $H 12 M$ coating hardness. 
Regression equation relating the hardness of the treated coating $P G-C P 4$ with the radiation power $W$ and the distance $L$ from the protective glass of the laser head to the sample treated surface, has the form:

$$
\mathrm{HV}=176.83+11.75 * W+1.63 * L
$$

The graphical interpretation of the regression equation (2) is represented by the $3 \mathrm{M}-\mathrm{XYZ}$ surface-graph shown in Fig. 3.

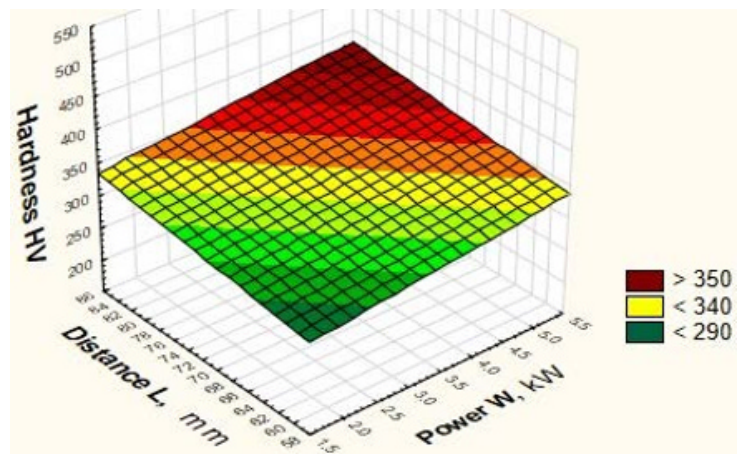

Fig. 3. 3M-XYZ surface-graph of the interactive effect of the radiation power $W$ and the distance $L$ on the hardness of the steel H12M coating.

The 3M-XYZ contour-graph of the interactive effect of the radiation power $W$ and the distance $L$ from the protective glass of the laser head to the sample treated surface on the coating hardness is shown in Fig. 4.

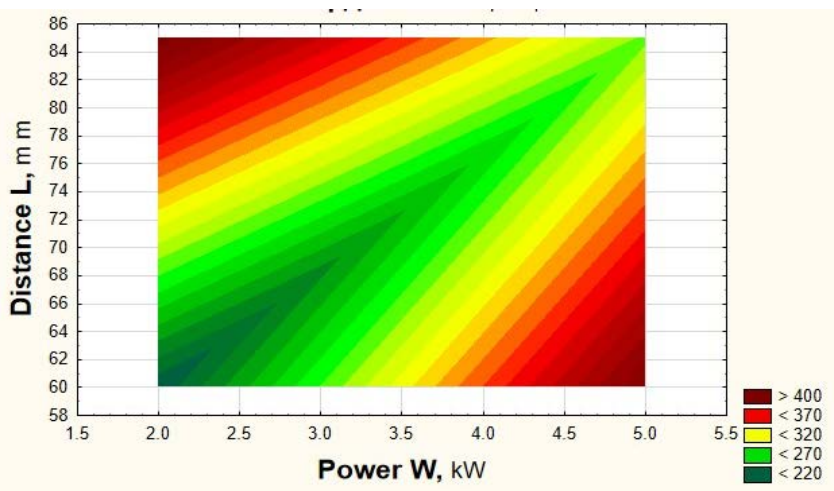

Fig. 4. 3M-XYZ contour-graph of the factors $W$ and $L$ interactive influence on the coating hardness.

The regression equation that relates the coating hardness to the longitudinal feed Spr of the laser beam and the distance $L$ from the protective glass of the laser head to the treated surface has the form:

$$
\mathrm{HV}=76.49+8.08 * \operatorname{Spr}+1.63 * L
$$

The graphical interpretation of the regression equation (3) is represented by the $3 \mathrm{M}$ XYZ surface-graph shown in Fig. 5. 


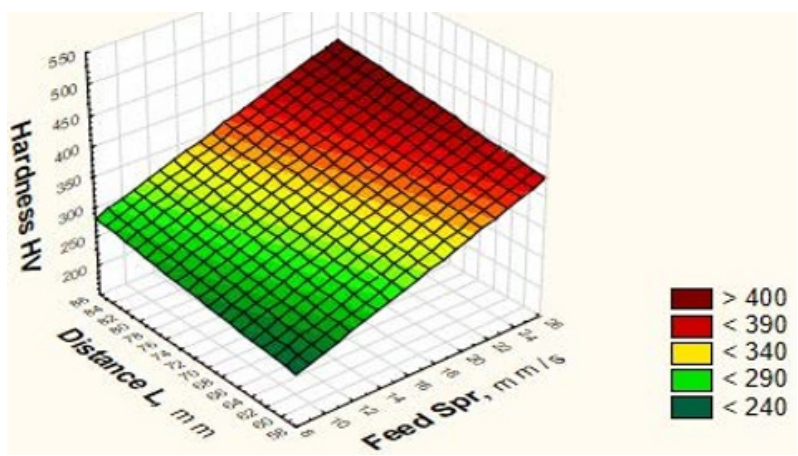

Fig. 5. 3M-XYZ surface-graph of the interactive effect of longitudinal feed Spr and the distance $L$ from the protective glass of the laser head to the treated surface on the coating hardness.

The 3M-XYZ contour-graph of the interactive effect of the longitudinal feed Spr and the distance $L$ on the coating hardness is shown in Fig. 6.

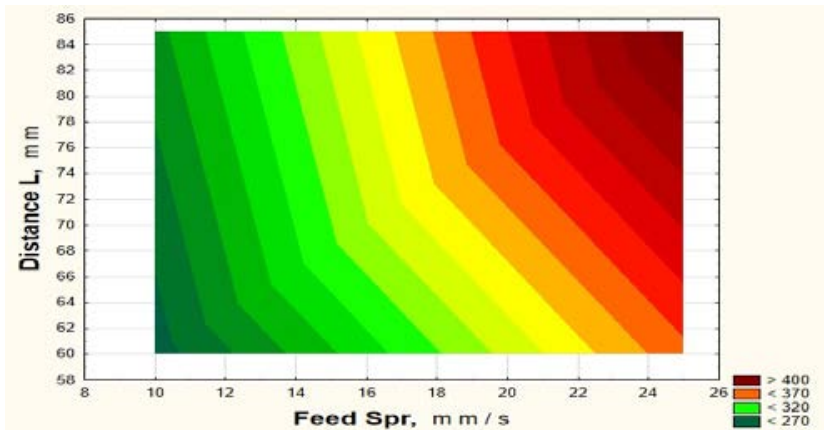

Fig. 6. The 3M-XYZ contour-graph of the interactive effect of the longitudinal feed Spr and the distance $L$ on the coating hardness of the H12M steel.

The multi-factor model that relates the PG-CP4 coating hardness to the independent factors of the laser processing process is represented by the regression equation in the code expression of the factors in the form:

$$
Y=336.125+17.625 * x_{1}+60.625 * x_{2}+20.375 * x_{3}
$$

It follows from equation (4) that at the independent factors increase, the coating hardness applied to H12M steel and treated with laser radiation increases. The longitudinal feed of the laser beam has the greatest influence on the coating hardness, followed by the distance from the protective glass of the laser head to the treated surface and the laser radiation power. It is impractical to use the regression equation (4) in the conditions of a real production process of laser coating processing, since in (4) the hardness function HV is represented in the codes designations of independent factors, despite the fact that the laser processing modes in production conditions are assigned in physical units measurement.

In this regard, a regression equation was established in which the hardness is associated with independent factors in their natural expression:

$$
\mathrm{HV}=153.545+11.75 * W+8.08 * S p r+1.63 * L
$$

In (4) the independent factors $x_{1}-x_{3}$ do not have the units, the factors $W$, Spr, and $L$ (in 5), have the units $\mathrm{kW}, \mathrm{mm} / \mathrm{s}$, and $\mathrm{mm}$, respectively, and the hardness parameter $\mathrm{HV}$ is in $\mathrm{kgf} / \mathrm{mm}^{2}$. 


\section{Discussion}

According to equation (5), the maximum hardness value HV 533 of the PG-CP4 coating applied to steel $H 12 M$ appears at the upper levels of independent factors $W, S p r$, and $L$. The steel H12M hardness in the delivery state is HV 207-255. A comparison of the above data shows that the application of a $P G-C P 4$ powder coating on $H 12 M$ steel using plasma and its subsequent laser treatment led to an increase in the initial hardness more than twice.

The hardness multi-factor model in the form of regression equations (1)-(5) and their graphical interpretations (Fig. 1) - (Fig. 6) are the project base for the development of effective technological processes for laser processing of the $P G-C P 4$ coating applied to steel $H 12 M$.

\section{Conclusion}

1. High-chromium tool steel $H 12 M$ is used to make matrix and punches of cold-pressing dies operating at pressures up to $1400-1600 \mathrm{MPa}$, as well as broaches and other cutting tools, in which the hardness of the surface layer plays an important role in ensuring high operational reliability.

2. A multifactorial experimental model of a $P G-C P 4$ powder coating hardness applied by plasma to steel $H 12 M$ and subjected to laser treatment has been established. The model relates the HV hardness parameter to the radiation power $W$, the longitudinal feed Spr of the laser beam, and the distance $L$ from the protective glass of the focusing head to the workpiece surface to be processed. Based on the multi-factor model, you can quickly assign a laser processing mode, which reduces the auxiliary time for performing a technological operation.

3. An increase in the independent factors $W, S p r$, and $L$ leads to an increase in the HV parameter. Longitudinal feed Spr has the greatest effect on the coating surface layer hardness then followed factors $W$ and $L$.

The obtained regression equations and their graphical interpretations are the project basis for the development of the laser treatment technological process of the PG-CP4 coating, which provides the required surface layer hardness.

4. The use of the model is relevant for enterprises that develop modern technologies of materials laser processing, but also for organizations and companies that design new highperformance laser equipment.

The study was conducted using the equipment of the Center for Collective Use (CCP) of promising and competitive technologies of the VlSU.

\section{References}

1. S.S. Yashkova, J. Young Sci. 1 (135), (2017)

2. N.A. Smirnova, A.I. Misyurov, Bul. of the Bauman Moscow state tech. un-ty, (2012)

3. I. Yadroitsev, I. Smurov, J. Phys. Procedia, 12 (2011)

4. S.A. Khairallah, A.T. Anderson, J. Mater. Process. Technol., 214 (2014)

5. Li Xiang Yang, Xiao Peng Peng, J. Prog. Nat. Sci., 11 (2001)

6. Xiao hu YE, Xi Chen, Chin. J. Lasers, 29 (2002)

7. S.A. Khairallah, A.T. Anderson, A. Rubenchik, at all, J. Acta Mat., 108 (2016)

8. Shibai Liu, Jichang Liu, Jinxuan Chen, at all, Influence of surface tension on the molten pool morphology in laser melting, DOI: 10.1016/j.ijthermalsci.2019.106075. 
9. Jan P. Kusinski, Sławomir Kąc, A. Kopia and at all, Review, AGH Un-ty of Sci. and Technol., Poland, (2012)

10. D.B. Purushothaman, M. Ponnusamy, J. Emerging Materials Research, 8 (2), (2019)

11. O.N. Voytovich, I.O. Sokorov, Bul. of the Bel.-Rus un-ty 2 (39), (2013)

12. M.M. Zhuravlev, O.P. Reshetnikova, Rus., Sci. and tech. Bul. of SSTU, 4 (68), (2012)

13. V.I. Shastin, M.I. Ovchinnikova, J. Young Sci. 21 (155), (2017)

14. V. Gusev, V. Morozov, and D. Gavrilovm, EasyChair Preprint 3114, (2020).

15. V.F. Losev, V.Yu. Morozova, and V.P. Tsipilev, Physical bases of laser processing of materials, Rus, Tomsk, (2011)

16. A.G. Grigoryants, I.N. Shiganov, at all, Bul. Laser-inform. 23 (398), (2008)

17. V.I. Yugov, Bul. Laser-inform. 23 (398), (2008)

18. V.P. Biryukov, A.A. Fishkov, D.Yu. Tatarkin, at all, DOI: 10.22184 / 19937296.2017.63.3.28.34 tech. equip. and technol.

19. R.S. Lakhkar, Y.S. Shin, J.M. Crane, J. Sci. and eng, A480 (2008)

20. V.G. Gusev, Theory and practice of planning multi-factor experiments, Rus., Vladimir, (2010) 